\title{
ENSAYO: NOTAS SOBRE JOHN CAGE Y LA LITERATURA
}

\section{NOTES ON JOHN CAGE AND LITERATURE}

\section{Pablo Montoya Campuzano ${ }^{* *}$}

* Texto leído en el coloquio "John Cage, el maestro del azar planeado, 1912-2012", celebrado en MedellínColombia, del 18 al 20 de septiembre de 2012.

** Pablo Montoya Campuzano, es novelista, poeta, ensayista, traductor, crítico y profesor de literatura colombiano. Realizó estudios de Música en la Escuela Superior de Música de Tunja y es graduado en Filosofía y Letras de la Universidad Santo Tomás en Bogotá. Obtuvo la maestría y el doctorado en Estudios Hispánicos y Latinoamericanos en la Universidad de la Nueva Sorbona-París 3. Actualmente es profesor de Literatura de la Universidad de Antioquia y Premio Rómulo Gallegos (2015), José Donoso (2016) y el Premio José María Arguedas (2017). 
Resumen

El presente texto sobre John Cage y la literatura está construido a partir de diez y seis pequeñas secciones. En ellas se realiza una travesía por diferentes momentos del proceso creativo de Cage y se relaciona con obras de la literatura y autores de la segunda mitad del siglo XIX y del XX. Finalmente se aborda la libertad en la creación de la composición musical y de la obra literaria y los diferentes sentidos que puede tomar.

Palabras clave: John Cage, música y literatura, creación artísica, música aleatoria, estética musical y literaria

\section{Abstract}

The present text about John Cage and literature is composed of sixteen little sections that illustrate a journey through different moments of Cage's creative process and is related to the authors and literary works of the second half of the XIX and XX century. Finally, freedom in the creation of both the musical composition and literary work and the different meanings that it can take are examined.

Keywords: John Cage, music and literature, artistic creation, aleatory music, music and literature aesthetics. 
"Estoy contra toda distinción entre pintura, música, literatura y las otras artes"1, decía John Cage en una entrevista que le hizo Jean-Yves Bosseur (Bosseur, 2000: 162). Bosseur le preguntó: “Y usted, ¿qué es?" A lo cual Cage respondió: “Comencé siendo músico, pues eso fue lo que le prometí a mi maestro Schoenberg. Pero ahora [estamos en 1970]... La música es otra cosa y no es mi culpa" (ibid.). Sin embargo, a Arnold Schoenberg, su discípulo norteamericano le parecía más un inventor que un compositor. Y esta diferenciación surgió porque Schoenberg no apreció un sentido apropiado de la armonía en las primeras obras que le presentó Cage (10). Sin ella, sentenció el alemán con un fuerte sentido de su responsabilidad pedagógica, la música se le convertirá a usted inevitablemente en algo así como golpearse la cabeza contra las paredes. Cage no se enfadó ante esta advertencia. Más bien sonrió, y dijo entre desdeñoso y provocador: "Pues bien, me la pasaré el resto de mi vida golpeándome la cabeza contra las paredes." (ibid.).

II

Quisiera detenerme en esta definición de Schoenberg - Cage es más un inventor que un compositor- y proponer un vínculo literario que quizás pueda resultar temerario. Pero lo haré con cierta prudencia. El puente que ideo es entre Cage y el Romanticismo. Acudo a Balzac y a uno de sus cuentos musicales llamado Gambara (1837) (Balzac, 1981: 73-138). Así como en Una obra maestra desconocida (1832) (39-72) Balzac prefigura la pintura de Cézanne e incluso la pintura abstracta del siglo xx, Gambara prepara una buena parte de la música contemporánea, atonal y atravesada por la nociones de ruido, de silencio y de azar, que en Cage tendrá a uno de sus más singulares exponentes. Gambara es un compositor extravagante, una suerte de lutier italiano radicado en el París de los años treinta del siglo XIX, que busca el secreto de la música y cree alcanzarlo a través de unas obras, ininteligibles para el narrador del cuento, pero acaso un poco más comprensibles para nosotros, que somos oyentes y lectores del siglo xxI. Sus obras imposibles las interpreta en un instrumento de teclado, inventado por él mismo, llamado Panharmonicon. Criatura capaz de explotar al máximo las fuentes de la armonía y la melodía hasta despedazarlas del todo y de reunir en su cuerpo las propiedades de una orquesta entera, el Panharmonicon tiene uno de los puestos fundamentales en un museo particular de la fantasía instrumental. Y me aventuro a ver en él un anticipo del piano preparado de Cage. En algún momento, Gambara se detiene y parece escuchar una inaudible gama de sonidos que, para el narrador, no es más que una especie de silencio ambiental interrumpido por los estertores y ruidajos que hace el músico italiano. Así como la pintura de Frenhofer - el personaje de Una obra maestra desconocida- pinta un caos de líneas rodeado de una especie de bruma sin forma, la obra que compone Gambara es una "estridente cacofonía", una "creación informe" que viola las reglas

Todas las traducciones son propias. 
de la composición y cuyos sonidos son "sonidos discordantes lanzados al azar" (113). El azar de Gambara, publicado en 1837, sin duda nos pone en esta senda que luego desembocará en los trabajos y en las especulaciones de John Cage.

\section{III}

Hay algo de estos músicos delirantes de la literatura romántica que me remite, mucho más que los compositores de carne y hueso de todo el siglo XIX, a la personalidad lúdica, traviesa y lúcida de Cage. En "El caballero Gluck", uno de los cuentos de Hoffmann publicado en 1809 (1984: 15-39), se toca una música prodigiosa en partituras donde no hay nada escrito. $Y$ sospecho que hay una sugestiva relación de continuidad entre esas partituras sin signos y las que Cage hará en donde, por lo demás, no hay notas aunque sí dibujos que deben guiar al intérprete por los meandros indeterminados de la obra musical. No olvidemos, por lo demás, que cuando a Cage le preguntaban si había signos o señales que pudieran poner a dialogar la danza con la música, Cage contestaba que entre ambas artes no había señales, y que si las había, debían provocar la indeterminación (Bosseur, 2000: 157). Hay otro personaje de Hoffmann, el consejero Krespel ("El consejero Krespel” (Hoffmann, 1984: 111159)), que insinúa también ciertos rasgos de la poética compositiva de Cage. Krespel, que es un constructor de violines y tiene raptada a una joven cantante excepcional que solo canta para él, hace construir su casa sin planos arquitectónicos previos. Los obreros de la obra llegan y Krespel les dice algo así como "en este hueco, caballeros, construyan algo que se parezca a un muro". Y cuando los trabajadores, en una atmósfera de risas y bromas frescas, terminan lo que podría parecerse a un muro, Krespel les dice que hagan en tal parte algo semejante a una ventana y luego más allá una segunda que no tendrá las mismas dimensiones de la primera, ni de la tercera ni de la cuarta. De tal modo que la casa que se construye queda tan perfectamente acabada que no se parece a ninguna otra casa en el mundo. Esta simpática historia me lleva a ciertas concepciones de Cage que hablan de una música que no se escribe, sino que se va haciendo progresivamente en un espacio apropiado para que ella exista. Cage se refirió varias veces, en las entrevistas que le hicieron, a la forma de su música. Él decía que la forma era un aspecto que no le interesaba y que ella solo podía percibirla el oyente (Bosseur, 2000: 156). El problema de las formas preestablecidas no le preocupaba en absoluto a Cage, o al menos al John Cage de la madurez. Y cuando veía asomado en los happenings cualquier indicio de intensión, perdía todo interés en la obra que escuchaba. La definición que da el compositor norteamericano de la música experimental ilumina a su modo la propuesta arquitectónica de Krespel: es aquella música en la que el compositor no sabe lo que va a pasar con ella en el momento en que se realiza (70).

\section{IV}

Con todo, quiero aclarar que establezco relaciones un poco ociosas. $\mathrm{Si}$ es verdad que Hoffmann, por ejemplo, creía, como Cage, en la unidad de la creación artística, 
es decir, que para él un verdadero artista era quien podía componer música, pintar frescos y escribir poemas, es menester precisar que entre la poética romántica y el pensamiento de Cage hay evidentemente grandes diferencias. Empezando por el espacio que ocupa entre unos y otro el asunto de la belleza. Mientras los románticos tipo Hoffmann, Balzac, Nerval y Victor Hugo, por citar los más representativos, hasta llegar al Baudelaire que escribe sobre los dramas de Wagner, creen que la música es el camino más idóneo para expresar las cimas inalcanzables de la belleza, Cage dirá que la belleza, o lo bello para mejor decirlo, no tenía nada que ver con sus pesquisas. Es más, en una entrevista que se le hizo sobre la música perfecta, bella y eterna de La Monte Young, Cage dijo que eran las cosas feas las que en realidad le interesaban más (cf. Bosseur, 2000: 167). “Lo feo no es lo feo sino la vida misma" (ibid.), decía Cage. Y es por esta razón que él trabajó más con ruidos que con sonidos puros. En su conferencia "El futuro de la música: Credo" (Cage, 2003: 3-7) Cage dice: "Donde estemos, lo que escuchamos es esencialmente ruido. Cuando no le prestamos atención, ese ruido nos molesta. Pero cuando lo escuchamos, lo encontramos fascinante" (3). Pero las consideraciones con Cage frente a la belleza no son así de claras. Un estudioso de su obra, David Revill², considera, por ejemplo, que la palabra que está en el centro de la apreciación estética de Cage es justamente la belleza. Sea esto cierto o no, inclinémonos mejor a pensar que la belleza en Cage admite la incertidumbre y el cambio, el azar y la imperfección.

\section{V}

Los románticos, además, ubicaban la belleza en ciertos terrenos límbicos abiertos al cielo o al infierno. Es más, se sabe que la expresión de lo bello en el Romanticismo estuvo ligada a la forma, a esa naturaleza móvil que exigía del artista dominarla a través de metamorfosis varias. Y tal vez esta indiferencia hacia lo bello podamos relacionarla con el mismo desdén con que Cage asumía el problema de la forma, pero también con el posible sentido de la música. Los sentidos que la música ofrecía, para los hombres del siglo xix, se podían concentrar en lo que se llamó la música pura y la música programática. Pero la una y la otra terminaban teniendo un sentido completamente manipulador. Habrá que esperar a que surja Stravinski para que se plantee la ausencia de semántica sonora. La música, según la célebre fórmula del Stravinki de la Poética musical (2011), tiene sintaxis pero en absoluto sentido. Cage, más radical que Stravinski, dirá que los sonidos creados por un compositor ni siquiera deben provenir de él mismo. En su artículo "Historia de la música experimental en los Estados Unidos" (1959) Cage se apoya en las palabras de Christian Wolff para decir:

La música es una resultante que existe simplemente en los sonidos que oímos, y no recibe ninguna impulsión de las expresiones del sí mismo o de la personalidad. La música es indiferente en su motivación, no saca su origen de ninguna psicología o intensión dramática, ni de ninguna concepción literaria o pictórica. (Cage, 2003: 76)

2 Cf. Revill, D. (1993). The Roaring Silence: John Cage —A life. Nueva York: Arcade Publishing. 
El sentido de la música, si es que existe, puede brotar entonces de la relación particular que entabla la obra con el oyente. Y esta relación, para Cage, es accidental, imprevisible, ilusoria. Y en lo que respecta a la sintaxis, ya se verá, sobre todo en su trabajo Empty words (1973-1975), cómo Cage enfrenta tal asunto.

\section{VI}

Estos personajes de la literatura musical romántica son emblemas de la rebeldía en el arte.Su relación con la sociedad es siempre conflictiva y usualmente están embriagados, no solo por sus propias concepciones artísticas, sino también por sustancias como el opio y el alcohol. Son paradigmas de la marginalidad, la enfermedad, la miseria, y por ello resultan tan llamativos. En esta perspectiva, me parece fundamental detenerse en uno de los escritores que más va a influir la obra y el pensamiento de Cage. También es un romántico y, sin duda, el primer gran rebelde de la historia de los Estados Unidos. Se trata de Henry David Thoreau. En la obra de Cage hay tres personas que actúan como pilares y que, al lado del budismo zen y el Libro de las Mutaciones, van a sostener las posturas artísticas y filosóficas del músico. Ellas son Erik Satie, James Joyce y Henry Thoreau. Thoreau hace un llamado a la negación de los gobiernos. Y lo propone desde la práctica de un individualismo que debe conducir no a un egoísmo caprichoso, sino a la realización plena de la libertad del ser humano. Thoreau en su ensayo sobre la desobediencia civil dice que la existencia de verdaderos hombres libres terminará negando la existencia de cualquier gobierno. "No habrá nunca un Estado verdaderamente libre e iluminado hasta que reconozca al individuo como el poder más alto e independiente" (Thoreau, 2011: 58). Estos perfiles sitúan las ideas de Thoreau no en el terreno de las utopías, pues casi todas las construcciones utópicas, desde la Antigüedad hasta nuestros días, devienen, por la regulación rigurosa en que se instauran, lugares siniestros donde se termina ejerciendo la autoridad de uno y otro modo, sino en el campo de la viabilidad tanto cotidiana como artística. Y el caso de la vida y la obra de John Cage están allí para demostrarlo, pues en él la libertad está en el centro mismo de la intersección que construyen el arte y la vida cotidiana. "No nací para ser obligado. Respiraré a mi manera." (39) "Si un hombre es libre de pensar, libre de soñar, libre de imaginar lo que no es por mucho tiempo lo que parece ser, no hay reformadores ni gobiernos insensatos que puedan impedírselo." (51). El sentido de estas frases de Thoreau puede ser perfectamente atribuible a Cage. Las palabras de Thoreau - "El mejor gobierno es aquel que gobierna menos (...) El mejor gobierno es aquel que no gobierna en absoluto" (3) - fundadas en un supuesto claramente anarquista, estará presente en varias obras de Cage. Mírese, por ejemplo, Etcétera (1973). Cage se basa en una comparación de Thoreau que aparece en la parte final del ensayo sobre la desobediencia civil. Thoreau compara al gobierno con un árbol, y a los individuos con los frutos que, al madurar, caen al suelo (58-59). Pues bien, Etcétera es una obra escrita para la orquesta de la Ópera de París, en la que los músicos poseen la facultad de desplazarse de una posición en la que no dependen del director de la orquesta a otra en la que esta dependencia se manifiesta. Es decir, por un lado el hacer música se asume desde el lado libertario y completamente individual y, del otro, se 
asume desde la noción misma del otro que representa el gobierno. Etcétera, de alguna manera, es ese árbol de Thoreau con sus propios frutos que se le escapan.

\section{VIII}

Hay otra obra de Cage que ilustra bastante bien el espíritu anarquista de Thoreau. Uno de los solos, el 35, de Song Books (1970) está basado sobre esas primeras frases del ensayo sobre la desobediencia: "La mejor forma de gobierno es la ausencia de gobierno" (Thoreau, 2011: 3). El solo en cuestión es una especie de himno, con estructura AABA. Pero antes de que el intérprete se enfrente al canto, se le propone portar la bandera de la anarquía, o una supuesta bandera del planeta Tierra, y mantenerla en alto durante el tiempo de la ejecución. Y en lo que tiene que ver con el carácter del canto mismo, Cage aconseja enturbiar tanto la altura y el timbre como la pronunciación del texto como si la voz del cantante no fuese diestra en estas faenas. Pero, además, hay otro solo, el 3, que brinda un particular homenaje al escritor y a su ciudad natal: Concord, en Massachusetts. El solo canta un texto de Thoreau sometido a todo tipo de intervenciones tipográficas que, a su vez, influyen en la variación de la intensidad como en la calidad del timbre de la voz. La línea melódica se construye esencialmente según las ondulaciones de un mapa de la ciudad de Concord (cf. Bosseur, 2000: 79-81). Cartografía y música se asocian aquí de tal modo que una intersección de rutas o la evocación de un medio de transporte en el papel estremecen el dispositivo electrónico que acompaña al cantante. La partitura se ve invadida $-\mathrm{y}$ tal caso se presentará también en otras obras de Cage, Atlas Eclipticalis (1961) y Études Australes (1974-1975), basadas en cartas astronómicas- de caminos y carreteras gráficos que el intérprete debe recorrer adecuadamente con su voz. Esta conexión de lo visual con lo sonoro, en lo que respecta al continuo homenaje que Cage hará de la personalidad de Thoreau, aparecerá en una obra que quisiera mencionar brevemente. 17 Drawins by Thoreau (1974) se elaboran a partir de diminutas fotografías de croquis de Thoreau sacados de su Diario; croquis con los que el mismo escritor intenta ilustrar sus reflexiones sobre la naturaleza. Con la ayuda del I Ching, ese libro que siempre acompañará las intensiones del artista, Cage determina el formato, la orientación, la superposición y el color mismo de las imágenes (cf. Bosseur, 2000: 98).

\section{IX}

Ahora bien, la utilización del I Ching, El libro de las mutaciones (2013), por parte de Cage obedece, me aventuro a pensarlo así, a esta búsqueda liberadora que Thoreau propone en sus escritos. Y es evidente, cuando se hace un recorrido por la vida de Cage, que el descubrimiento de la filosofía oriental a través de los cursos que imparte Suzuki sobre budismo zen, ${ }^{3}$ como el descubrimiento del grupo delos trascendentalistas, del cual formó parte Thoreau junto a Ralph Waldo Emerson, se dan, si no simultáneamente, en todo

"Después del descubrimiento de la filosofía de Coomaraswamy y del encuentro con Gita Sarabhai, Cage acude durante dos años a los cursos de Suzuki sobre el budismo zen en la Universidad de Columbia." (cf. Bosseur, 2000: 24). 
caso de manera dialógica. El horizonte propuesto por los hexagramas del I Ching libera entonces al compositor de sus gustos y sus disgustos, de sus fantasmas personales y cargas emotivas y lanza al individuo a los terrenos del azar. "Un músico disciplinado, dirá Cage, no es alguien que se fije a reglas estrictas o que respete estrictamente las reglas, o que interprete escrupulosamente una obra, sino alguien que sabe olvidar, que es capaz de desembarazarse de toda idea de gusto o de disgusto, es aquel que no busca ni intenta construir" (Bosseur, 2000: 68). Iniciando los años cincuenta, John Cage se sumerge en los dos volúmenes del I Ching, cuya gama de oráculos de la antigua China lo llevarán a establecer un sistema de composición "impersonal". Un sistema que terminará conduciéndolo a una suerte de poética, en donde él, como compositor, se consagra a plantear preguntas cuyas respuestas, nacidas del azar, abrirán su espíritu al mundo exterior.

\section{$\mathbf{X}$}

Pero el azar en la música de Cage no solamente está vinculado al I Ching, sino también a las cartas mágicas y del Tarot, y al tiraje de los dados y las monedas. El procedimiento, aunque en cierta medida diferente en cada una de estas modalidades, concluye en la elaboración de un azar que no supone, como pensaba Pierre Boulez, una especie de irresponsabilidad del compositor con su propia obra ( $c f$. Bosseur, 2000: 40), sino una actividad liberadora que vincula tanto el creador como al intérprete. Esto concierne al trabajo propiamente poético de Cage. Experimentando a partir de tablas de palabras fundadas sobre una muestra de vocales, y utilizando monedas, Cage comenzará a escribir una obra poética que al recurrir al azar no elimina ni el rigor ni la selección. Pues la selección en Cage reside justamente en la naturaleza de las preguntas que mueven la creatividad del compositor. Y estas preguntas establecen de nuevo un lazo entre las ideas de Thoreau y Cage. Valga la pena señalar que, frente a las preguntas, Cage no mantendrá una posición ni afirmativa ni negativa, sino que habitará un especie de interregno que reúne ambas circunstancias. Como en Thoreau, que piensa que tanto el "sí" como el "no" son propiamente mentiras (Bosseur, 2000: 37), Cage opina que la verdadera respuesta, inestable y ondeante, jamás absoluta y autoritaria, está en un algún lado de la unión de ambas posibilidades. Juego de opuestos que edifican la escurridiza y ficticia unicidad del mundo y de la existencia, y que tiene que ver, por supuesto, con las ideas del budismo zen. En resumen, se podría decir que al acudir a los procedimientos del azar, Cage intenta, al mismo tiempo, determinar la naturaleza del material sonoro y su organización y volver más diáfana su personalidad de compositor y poeta. De lo que trata, en fin, es de hacer una música, sonora o lingüística, que interrogue al intérprete y al oyente y deje de darle órdenes estéticas. Que lo aleje de lo previsible y lo enfrente a lo accidental.

\section{$\mathbf{X I}$}

Etimológicamente, "sintaxis" posee una connotación militar. El verbo griego syntassein significa alinear un grupo de soldados para la batalla. Por ello, a la sintaxis 
como al gobierno solo hay que obedecerle o desobedecerle. Y Cage opta por lo segundo. Desbaratar sintaxis lleva necesariamente a dinamitar semánticas y esto significa desmilitarizar el lenguaje. La desmilitarización del lenguaje la han señalado algunos estudiosos de la obra de Cage, entre ellos Norman Brown (Bosseur, 2000: 68) y Diane Mullin ${ }^{4}$. De hecho, esta relación anarquista con las palabras es lo que se presenta en Empty words, obra dividida en cuatro partes, en la que Cage se basa en pasajes del diario de Thoreau y cuyo sistema de composición remite una vez más a los procesos aleatorios del I Ching. Pero, como dice Dawn Akemi Sueoka, ${ }^{5}$ es justamente desde el trabajo laborioso de la sintaxis que Cage propone otras lecturas de los textos de Thoreau. La literatura se vincula con la música para proponer una estética cuyo rumbo es la negación de todo poder lingüístico. Y es que Thoreau, hasta en sus concepciones sobre el silencio - "La mejor comunicación que obtienen los hombres reside en el silencio" (Bosseur, 2000: 42), decía el escritor-, será como una especie de vector permanente en la construcción de la obra de Cage. Empty words ofrece en sus cuatro partes un singular tratamiento que desarma sistemáticamente las palabras de Thoreau. Cage, en realidad, ama y admira tanto al escritor de Massachusets que termina disolviendo, en una libertaria incomprensión, su propio mensaje libertario. En la primera de sus partes, se eliminan las oraciones, y solo hay frases, sílabas, palabras y letras. En la segunda, se eliminan las oraciones y las frases, y solo hay palabras, sílabas y letras. En la tercera, se eliminan oraciones, frases y palabras, y solo hay sílabas y letras. Y en la cuarta, se eliminan oraciones, frases, palabras y sílabas, y solo quedan letras. Se podría diseccionar Empty words tratando de seguir rigurosamente las reglas propuestas por Cage. Pero acaso lo mejor sea apoyarse en Akemi Sueoka ${ }^{6}$ cuando dice que es el fracaso de esta supuesta normativa lo que otorga a la obra su poderosa energía artística. Tales trozos efímeros se resisten, en realidad, a una interpretación definitiva. Y lo que los hace inquietantemente "bellos" es su condición proclive a lo cambiante y a lo parcial. Empty words se concibió para que durara aproximadamente doce horas. Cage imaginaba este juego de palimpsestos interpretándose a lo largo de una noche. Las palabras desmembradas deben irse mezclando con los ruidos ambientales que las gentes hacen al abrir y cerrar las puertas y ventanas de sus viviendas. De este modo, se opera una especie de puente progresivo, de múltiples sentidos, entre texto y sonido. El mismo Cage define así su obra:

Empty words es una transición de la literatura hacia la música; en cada parte se quita un elemento sintáctico y se llega así a las letras y al silencio, es decir, a la música; a fuerza de reducir los elementos del lenguaje se presenta una aproximación al núcleo de la música. (Bosseur, 2000: 185).

4 Cf. Mullin, D. (2012). Emptying words: Demilitarizing, Denoting, and Delight. En http://www. quodlibetica.com/emptying-words-demilitarizing-denoting-and-delight/ Consultado el 10 de julio de 2016.

5 Cf. Akemi Sueoka, D. (2012). Hidden harmonies in John Cage's 'Empty Words'. En http://jacket2.org/ article/hidden-harmonies-john-cages-empty-words Consultado el 10 de julio de 2016.

6 Ibid. 
Como propone Akemi Sueoka ${ }^{7}$, en un universo lingüístico como el que hemos construido las sociedades humanas, dominado por la mentira y la manipulación de la política, la religión, la guerra, el comercio, la genética y la publicidad, la obra de Cage no deja de ser una senda poética oxigenante.

\section{XII}

Un último homenaje a Thoreau que quisiera mencionar es el que realiza Cage en su obra Mureau (1970), homenaje que tiene una tendencia literaria porque fue previsto para publicarse en una revista o en un libro. Afecto al juego de las palabras, Cage une aquí Música y Thoreau. De nuevo se utilizan fragmentos del Diario en donde el escritor se refiere particularmente a la música, el sonido y el silencio. Nuevamente aparece el deseo de Cage de liberar la lengua inglesa de la opresión de la sintaxis produciéndose así una suerte de sinsentido. Jean-Yves Bosseur explica Mureau de esta manera:

Emana de ella una mezcla de letras, sílabas, palabras, expresiones, frases que invitan a considerar de un modo especial el fenómeno del tiempo de la lectura y el espacio de la página, las sonoridades fonéticas y sus propiedades semánticas como diferentes facetas de un mismo fenómeno, creando con ello una serie de movimientos cuyas repercusiones limitan con lo infinito. (2000: 125).

\section{XIII}

Otra figura literaria esencial en la obra de Cage es James Joyce. Son varias las obras, como en el caso de Thoreau, en las que el escritor irlandés aparece como referente o como personalidad homenajeada. De la obra de Finnegans Wake (1939), Borges decía con cierto aire de incómoda perplejidad que es un libro incomprensible, fruto de un largo periodo de dieciséis años de trabajo literario (Borges, 2007: 535). Laberinto verbal con poca eficacia. Eficacia que, según la nota de Borges, tiene que ver con el asunto de la comprensión. En resumen, Borges define así el último libro de Joyce: "Finnegans Wake es una concatenación de retruécanos cometidos en un inglés onírico y que es difícil no calificar de frustrados e incompetentes" (ibid.). Y lo que le atrae a Cage del libro - esto es, los diferentes sentidos que otorgan las palabras compuestas (por ejemplo, banistar que significa a la vez balaustrada y estrella, o laughtears que significa risa y lágrima)—, a Borges le parece la ejecución de un juego sin mayor fortuna. En donde el argentino hallaba algo así como artificio y confusión, el norteamericano encontraba una experiencia interminable y atractiva. A ambas sensibilidades tendientes al anarquismo - Borges sería algo así como un anarquista de derechas, mientras que Cage sería algo así como un anarquista alternativo-, lo que las diferenciaría, a primera vista, sería el repudio de toda vanguardia del primero y los afectos que esta misma le procuraba al segundo. Con todo, Cage amaba en Joyce estos retruécanos "frustrados" porque había en algunos de ellos una esencia budista que Borges acaso jamás intuyó. Para justificar su gusto por estos trabajos de Joyce, Cage contaba una historia de su

\footnotetext{
Ibid.
} 
maestro Suzuki. Al asistir a un congreso de filosofía en Hawai, a Suzuki le preguntó un filósofo qué pensaba de una cierta conferencia. Suzuki respondió que estaba bien pero que, en el zen, lo importante es la vida. Al otro día, el mismo filósofo le pidió la opinión a Suzuki sobre otra conferencia, a lo cual el maestro japonés respondió que estaba bien pero que, en el zen, lo importante es la muerte. Asombrado el filósofo le dijo que cómo era posible afirmar un día la vida y al siguiente día la muerte. Suzuki dijo entonces que en el zen no había mayor diferencia (cf. Bosseur, 2000: 182). Esta conjunción de los opuestos, que uniría a Thoreau y Joyce con el pensamiento oriental, está pues en la base de la elección musical y literaria de Cage.

\section{XIV}

La composición de Roaratorio (1979) sobre el Work in progress de Joyce da la impresión de ser una obra hecha para que acompañe, como fondo sonoro, una exposición especial de la vida y obra del escritor irlandés. Pero, según algunos, podría ser también una obra apta para provocar suicidas estados de confusión. Lo uno o lo otro, Cage no rechazaba ninguna de estas recepciones. Roaratorio es una obra donde se confabula el texto joyceano, intervenido por el propio Cage a través de cinco reescrituras sucesivas. Hay como un "libreto" conformado por estos diferentes recorridos de la obra de Joyce donde una vez más el azar predomina, sobre todo en la cuarta reescritura que está determinada por el tiraje de las monedas. La primera está integrada por 862 mesostics sobre el nombre de James Joyce. El mesostic, valga la pena aclararlo, es una invención consistente en escribir varias líneas horizontales de una poesía, una encima de la otra, y relacionarla con una palabra que se escribe verticalmente a través de una colocación estratégica de cartas. El libreto, en rigor no se lee, sino que, alternativamente, se habla, se canta, se susurra, se silba, se grita, se puja. Y está acompañado por un aluvión de miles de sonidos que el mismo Cage extrajo de su lectura de Finnegans Wake. Así, en tanto se ejecuta el libreto, brotan aleatoriamente diversos sonidos tales como truenos, vientos, lluvias, cantos de gallo, llantos de niños, campanas, explosiones, cristales rotos, cantos de pájaros. Pero hay otro factor sonoro notable de esta obra: la presencia de canciones folklóricas y populares irlandesas, de tal modo que al escucharse esta intervención, de connotaciones digamos nacionalistas, se siente acaso la vitalidad de la calle o el pub dublineses. Finnegans Wake está surcado de textos y melodías de canciones irlandesas, muchas de ellas cantadas en gaélico. Esta presencia popular prodiga a la obra su carácter circense, tal como lo concebía Cage. No hay que olvidar, en este sentido, el subtítulo que acompaña a Roaratorio: An Irish Circus.

\section{XV}

Noción de circo que envía, por un lado, a la parada satieana, y por otro, al pálpito vital que empuja a los acontecimientos llamados Musicircus. En ellos, se retoma una vieja idea del compositor Charles Ives, tan admirado igualmente por Cage, que siempre soñó con una sinfonía del universo, en la que debían intervenir varios grupos de músicos reunidos en un sitio natural - valle, montaña, colina o ribera - para producir un feliz 
desorden sonoro. De hecho, me parece que en Roaratorio, así como en los Musicircus, se presenta un fenómeno bastante sugestivo: se logra una ausencia de intensiones debido a la multiplicación de intensiones. 0 para decirlo de otro modo, los elementos que integran Roaratorio no se relacionan entre sí, aunque una profunda correspondencia se establece con el texto de Joyce. Cage en su explicación del proceso creativo de esta obra, al recibir el premio Carl Sczuka en 1979, decía algo que explica en parte su propósito: "Espero que Roaratorio actuará para introducir a la gente a los placeres de Finnegans Wake que están del lado de la poesía y el caos, pero también del lado de la seguridad y del respeto de la ley."

\section{XVI}

La figura de Joyce estará presente en el último proyecto compositivo de Cage, proyecto que no pudo llevar a cabo porque lo sorprendió la muerte, el 12 de agosto de 1992. Se trata del ballet Ocean concebido para la compañía de Merce Cunningham. El ballet se estrenó en Bruselas, en 1994. La partitura, para 112 instrumentistas, no cuenta con un director de orquesta y se basa en los principios de total independencia. Cage imaginó una ubicación circular de los músicos. Los bailarines debían dirigirse progresivamente hacia el centro del espacio constituido. Mientras que el público se situaba entre estos últimos y la orquesta. Lo cual daba la impresión de una conformación de tres círculos concéntricos. Como Cage no terminó de escribir esta obra, sus amigos David Tudor y Andrew Cluver lograron darle término a la partitura a partir de conversaciones que tuvieron con su amigo. Lo que resulta notable, además de que Ocean sea una de esas obras que condensan las inquietudes esenciales de Cage en torno a la música, la danza y la literatura, es que el título que escogió para su obra póstuma fuera el mismo título que Joyce mantuviera para un proyecto que debía ser la continuación de Finnegans Wake. El gesto de Cage se levanta entonces como una especie de homenaje inacabado hacia el escritor irlandés. Un Work in progress, como lo expresa Jean Yves Bosseur (2000: 152), sometido a los vaivenes de la vida y la muerte. Bella manera de hacer resonar un periplo existencial y una postura poético-musical, la de John Cage, con la de un hermano mayor, James Joyce, que también transitó un siglo vertiginoso dueño acaso de las mayores rupturas dadas en la historia del arte. Cage y Joyce, dos ríos disueltos finalmente en el océano del tiempo o, para utilizar un concepto caro al budismo, en la nada.

8 Cage, J. (1979). On having received the Carl Sczuka Prize for Roaratorio. Tomado de http://www.ludions. com/aru/radio/misc/roaratorio.html, consultado el 10 de julio de 2016. 


\section{John Cage}

Posees la certeza de quien se sabe vivo. Abierto a todas las posibilidades. La de ahora es este bosque de árboles sin hojas. La lluvia ha cesado. La escuchaste. Sus voces te parecieron únicas. Pero las olvidaste. La de ahora son tus pasos sobre la tierra mojada. Oyes cómo suena bajo tus botas. La de ahora son esos hongos que crecen milagrosamente. Acaricias sus sombrillas y el relieve de los tallos. La canasta está llena. Y su peso es, en realidad, el peso del universo. Algo te están diciendo los hongos. Pero cuando crees comprender, un velo se te impone de nuevo. Te detienes antes de entrar en la cabaña. Cierras los ojos. El mundo vibra atravesado por un rumor inacabable. Tú crees saber lo que dice. Pero también lo olvidas. (Montoya, 2016: 258) 


\section{Bibliografía}

Borges, J. L. (2007). Obras completas. IV. Bogotá: Emecé Editores.

Bosseur, J. Y. (2000). John Cage. París: Minerve.

Balzac, H. (1981). Le chef d'œuvre inconnu. París: Garnier-Flammarion

Cage, J. (2003). Silence. Conférences et écrits. Ginebra: Éditions Héros-Limite.

Hoffmann, E. (1984). Nouvelles musicales. París: Éditions Stock.

I Ching. (2013). Versión del chino al alemán por Richard Wilhelm. Traducción al español de D. J. Vogelman. Santafé de Bogotá: Editorial Solar Ltda.

Montoya, P. (2016). Terceto. Bogotá: Literatura Random House.

Strawinsky, I. (2011). Poétique musicale. París: Flammarion.

Thoreau, H. (2011). Sobre la desobediencia civil. Traducción María Cristina Restrepo. Medellín: Editorial Universidad de Antioquia. 